\title{
Locomotor Development of Children Aged 3.5 to 5 Years in Nursery Schools in Greece
}

\author{
Aggeliki Tsapakidou ${ }^{1}$, Sofia Stefanidou ${ }^{1} \&$ Eleni Tsompanaki ${ }^{1}$ \\ ${ }^{1}$ Department of Early Childhood Education, University of Western Macedonia of Greece, Greece \\ Correspondence: Aggeliki Tsapakidou, Department of Early Childhood Education, University of Western \\ Macedonia of Greece, 3rd km of the National Florina - Niki Road, P.O. 21, Florina 53100, Greece. Tel: \\ 30-238-505-5093. E-mail: atsapakid@uowm.gr
}

\author{
Received: January 12, 2014 Accepted: February 17, 2014 Online Published: March 19, 2014 \\ doi:10.5539/res.v6n2p1 URL: http://dx.doi.org/10.5539/res.v6n2p1
}

\begin{abstract}
The present study was designed to examine the effect of an intervention program on nursery school children's locomotor development. Participants were 98 children (50 boys and 48 girls) aged 3.5-5 from three preschools of the Municipality of Kalamaria, in Greece. The 49 children who formed the experimental group participated for two months in 16 organised courses, designed to develop basic motor skills. The measurement tool used to evaluate the sample before and after the intervention was Urlich's test of gross motor development (TGMD-2, 2000). The statistical analysis showed that the experimental group after the intervention program performed better than the control group without statistically significant differences between the sexes. The results showed that educators should incorporate corresponding motor programs in their daily schedule, although there is currently no curriculum for nursery school that includes them.
\end{abstract}

Keywords: pre-school age, nursery education, motor skills, intervention program

\section{Introduction}

A child's development is a holistic process, in which movement is of particular importance, as through movement and mobile games children learn about themselves, their bodies, space, and have the opportunity to come into contact and interact with their peers (Zimmer, 1992). Children learn how to move and learn through movement (Gallahue, 2002) and in that way they discover the world (Zimmer, 1992). Canada's physical education curriculum handbook indicates that children in the first years of their life should be physically active. By the first year the child should play on the floor at various times during the day, while up to the age of four he/she should be involved for at least 180 minutes a day in physical education activities of any intensity, in different environments and in various activities that develop locomotor skills (Tremblay et al., 2012). According to the National Association for Sport and Physical Education in the U.S. (NAPSE, 2002), preschool children should participate daily for at least one hour in organized physical education activities and one hour in spontaneous activities.

Physical education for children aged 2-5 years is very important and should be focused on kinetic movement activities and games that entertain children (Timmons, Naylor, \& Pfeiffer, 2007).

Motor development according to Gallahue (2002) is a gradual progressive change of the kinetic behavior of the individual, caused by the interaction with the environment and the motor task. Gallahue (2002) defines basic motor skills as an organised series of basic movements that involve the combination of kinetic models of two or more body parts and categorises them as stabilisation, travelling and handling skills. Preschool and elementary age is the appropriate and fundamental time for children to develop basic motor skills (Gallahue \& Ozmun, 1998).

Many studies reinforce the view that an organised motor/movement program promotes motor development in preschool children (Derri et al., 2001; Kambas et al., 2005; Venetsanou \& Kambas, 2004; Barta et al., 2007; Livonena et al., 2011).

The aim of motor programs is the development of basic skills, the activation of imagination and creativity (Cheung, 2010), the strengthening of cognitive skills (Lupu, 2011) and the development of self-esteem and 
social relations (Zachopoulou et al., 2007; Ward, 2010). Through the development of basic skills, coordination is particularly enhanced; this is a very important factor for children's further education (Lupu, 2011).

Hardy (et al., 2009) conducted research on a sample that consisted of 29 schools in Australia and demonstrated the importance of motor programs for children. Through structured activities directed by the teacher, children improved basic motor skills that could have long-term effects, as they supported the hypothesis that children would participate as adolescents and adults successfully in sports.

Venetsanou and Kambas (2010) studied the environmental factors that affect children's motor development. They concluded that mothers' socio-economic status and educational level played an important role as well as preschool educational centers through motor interventional programs.

The case of the interaction of motion with learning prompted many researchers to study how motor programs could be implemented in teaching other subjects. Gellens (2005) showed that movement promotes brain development. Likewise Collins, Vikki \& Yates (2005) pointed out that movement through organised activities can enhance the learning of language and literature, and Moomaw (2005) supported the strengthening of understanding mathematical concepts through movement activities.

Natsiopoulou (et al., 2010), studied the effects of a health educational program based on motor activities and games for preschoolers. The results were encouraging as children's knowledge of healthy and an unhealthy lifestyle was deeper after the intervention program. It seemed that a properly organised program helps children develop responsibility in matters of health and physical activity (Vale et al., 2011).

The importance of movement development and the contribution of motor programs to a child's development are commonly accepted, however, the results for gender as a factor are contradictory. As Hardy et al. (2009), Linovena et al. (2011) and Piek et al., (2012) support the acquisition of basic motor skills differs depending on gender, while Pollatou et al. (2005) argues that there is no difference in gender in relation to motor development.

In Greece, the importance of physical education in preschool is recognised and this is why it is included in the curriculum for kindergartens, which has been designed by the Pedagogical Institute of the Ministry of Education, Lifelong Learning and Religious Affairs. Since 2003, the cross curriculum framework (D.E.P.P.S.) for kindergarten was formed, by a presidential decree, where physical education had an important place in the daily program. The purpose was to promote physical, mental, social and emotional development through motor activities. The child's body was considered a great learning tool and the objectives of physical education were formalised. The goals set were the development of basic motor skills (stabilization of movement and control) and the development of motor concepts such as perception of space and rhythm, the activation of imagination and creativity, strengthening of cognitive skills, learning rules of hygiene, so as to develop confidence and social skills for effective collaboration with peers. It is noteworthy that for nurseries in Greece there is no syllabus, rather a standard operator's manual. Nursery schools are pre-school centers that accommodate children up to age five, when they attend kindergarten. The model regulation that the ministry of public administration and decentralization, the ministry of interior and the ministry of health and welfare co-decided, was published in Gazette on 22/4/2002. According to this regulation, in the flexible program that nursery schools have, the daily activities are aimed at harmonious psychophysical development of children. Thus, a simple reference has been made stating that in the period from 9:30 am until 12:00 noon gymnastics, rhythmic education and psychomotor activities and games can be performed.

Incomplete studies in motor development of children attending nursery schools and the absence of curriculum structure (syllabus) to provide a guide for the educator were the motivation for this research.

The purpose of this research was:

- To study the effect and the efficacy of an intervention program for motor development of children 3.5 to 5 years old in nursery schools.

- The detection of any changes in the performance of motor skills in running, gallop, hopscotch, jumping stride, the horizontal jump and lateral run-gliding.

- The performance of motor skills in both genders.

\section{Methods}

\subsection{Sample}

The sample consisted of 98 children, 50 boys and 48 girls, aged 3,5 to 5 years old, from three kindergarten schools in Kalamaria of Thessaloniki in Greece. The 49 children (22 boys and 27 girls) constituted the experimental group, which took part in the training program, while the remaining 49 children ( 28 boys and 21 
girls) were part of the control group. Prerequisite for sample selection were the children not to participate in extracurricular sports activities, such as music-ballet and swimming. Thus, children that were found to be engaged in similar activities, participated and were evaluated in the basic motor program, but the results of their evaluations were not counted. Prior to the survey, the consent of the director of the kindergarten and the parents of all children in the sample was asked.

\subsection{Urlich Test}

To evaluate children's coarse motor skills, Urlich test of gross motor development (TGMD-2, 2000) was used, which is designed for children from 3-10 years. The test is divided into two sub-tests, a) in sub-test of travelling skills and b) in sub-test of handling skills. In the present study, only the sub-test of travelling was examined. This sub-test examined and assessed the correct implementation in: 1) running, 2) galloping, 3) hop scotching, 4) the jump stride, 5) the horizontal jump and 6) in the lateral run-gliding.

Time measurement and evaluation of each child lasted about 15-20 minutes and the test was performed on each child individually or in some cases in small groups of two and three children. Each test was performed twice in each child, since there had been a verbal explanation and demonstration by the investigator and both efforts were evaluated. Finally, both attempts have been calculated and the sum was matched according to child's age. The creator of this test sets norms for age, so depending on the age of the child and the results of the tests the level of motor development is determined. The rating levels were: very high, high, above the average, average, below average, poor, very poor. The test of gross motor development TGMD-2 by Ulrich is the second and most advanced version of the original TGMD created in 1985 and is considered a valid tool for measuring motor skills for children three to ten years. The validity and reliability of the test was found by Evaggelinou, Tsigilis and Papa (2002) in their research in 644 children, in Greece.

\subsection{Experimental Procedure}

The measurement of the level of motor development was performed in two phases, before and after implementation of the intervention program. The interventionist program applied for two months in the experimental group twice a week, and consisted of 16 subjects. Each lesson was divided into three parts: a) warm-up, b) the main course and c) the cool-down, and lasted 30-40 minutes. The activities of the program had as a main aim the development of basic motor skills and specific objectives such as getting to know with the body, perception of space and rhythm, balance, coordination, attentiveness, teamwork and cooperation, and finally enhancing creativity. The program took place at the school's gym and several props were used such as hoops, balls, ribbons, skipping ropes, bags balance (bean-bags), fabric and plain cardstock papers. Most activities were accompanied by music and in others, teacher used the tambourine. The classes were implemented by educators in both courses of the experimental groups. Curriculum design and explanations of all courses were given to all educators. The control group, who was parted by the other two courses, followed their daily schedule.

\section{Results}

Table 1 shows the averages and standard deviations of the initial and final measurement of the control group and the experimental group. To investigate the interaction of the 'program' and 'measurement' factors t-test was used. The analysis showed that the first measurement before the implementation of the program there was no statistical difference between the two groups, $\mathrm{t}=0.235, \mathrm{p}=0.815>0.005, \mathrm{df}=96$. Unlike this, the analysis of the second measurement, after the intervention showed a statistically significant difference in the two groups, $\mathrm{t}=-5.647, \mathrm{p}=$ $0.000<0.005, \mathrm{df}=96$. From the examination of the mean values it also seemed that the experimental group at the second measurement had higher values on the performance of $(10.61>8.18)$.

Table 1. Group statistics

\begin{tabular}{llcccc}
\hline & Group & $\mathrm{N}$ & Mean & Std. Deviation & Std. Error Mean \\
\hline pre-test score & control group & 49 & 7.3265 & 2.03498 & .29071 \\
& experimental group & 49 & 7.2245 & 2.25708 & .32244 \\
post-test score & control group & 49 & 8.1837 & 2.14742 & .30677 \\
& experimental group & 49 & 10.6122 & 2.10966 & .30138 \\
\hline
\end{tabular}

Table 2 and Table 3 show the mean and the standard deviation of the performance of the control and experimental groups separately, for each gender. The t-test showed that in the control group there is no 
statistically significant difference concerning the sex factor in any of the two measurements $\mathrm{t}=0.685, \mathrm{p}=0.497>$ 0.005 , df $=47$ in the initial evaluation and $t=0.784, p=0.437>0.005, \mathrm{df}=47$ in the final measurement. Respectively, the experimental group did not reveal any significant differences between boys and girls, $\mathrm{t}=$ $-1.541, \mathrm{p}=0.130>0.005, \mathrm{df}=47$ in the initial evaluation and $\mathrm{t}=-0.741, \mathrm{p}=0.462>0.005, \mathrm{df}=47$ in the final measurement.

Table 2. Control group

\begin{tabular}{lccccc}
\hline & Gender & N & Mean & Std. Deviation & Std. Error Mean \\
\hline pre-test score & Boy & 28 & 7.5000 & 2.08167 & .39340 \\
& Girl & 21 & 7.0952 & 1.99762 & .43592 \\
post-test score & Boy & 28 & 8.3929 & 1.95011 & .36854 \\
& Girl & 21 & 7.9048 & 2.40634 & .52511 \\
\hline
\end{tabular}

Table 3. Experimental group

\begin{tabular}{lccccc}
\hline & Gender & N & Mean & Std. Deviation & Std. Error Mean \\
\hline pre-test score & Boy & 22 & 6.6818 & 1.86155 & .39688 \\
& Girl & 27 & 7.6667 & 2.48069 & .47741 \\
post-test score & Boy & 22 & 10.3636 & 2.34105 & .49911 \\
& Girl & 27 & 10.8148 & 1.92228 & .36994 \\
\hline
\end{tabular}

\section{Discussion}

The results of this research were encouraging as the statistical analyses showed a significant improvement of basic motor skills in children of the experimental group who attended the intervention program. Children in the control group had a very slight improvement in the second evaluation, presumably due to their maturity and the fundamental motor activities implemented by educators in their daily schedule.

The results are consistent with Wang's (2004) research where preschool children, through a creative kinetic program developed fundamental motor skills (Piek et al., 2012; Venetsanou \& Kambas, 2004; Reilly et al., 2006; Kromboholz, 2012).

According to Livonena (et al., 2011), even a two-week-long motor program is sufficient to improve movement skills, and this is significantly less than the two months that this research's intervention program spends in nursery schools.

The combination of music and movement and the use of the tambourine, as well as rhythmic activities that were included in this mobility program played an important role in the implementation of the program of this research, as it enhanced children's motor performance (Zachopoulou et al., 2004; Derri et al., 2001).

The results of the research showed that boys and girls do not differ in kinetic performance of movement skills. The results corresponded with Pollatou et al., 2005, Butterfield et al., (2002) and with Zachopoulou and Makri (2005), who argued that the 'gender' factor does not affect kinetic development. Urlich (2000), on locomotor skills, lists a common table in the age norms of gender, while in manipulative skills for the calculation of the kinetic performance he distinguishes the two sexes, reinforcing the view that there is no difference between sexes at least in locomotor skills.

Much research has been done on kinetic education and the effectiveness of motor programs during the preschool years, as seen in the introduction section. In Greece, pre-school education, as mentioned earlier in this research, is divided into nursery schools and kindergartens. Kindergartens are part of the fundamental education and therefore, there is curriculum design and an analytical program. As far as it concerns physical education, aims and objectives are being analysed and suitable activities are proposed. The paradox in Greek reality is that for children in nursery school there is no such curriculum. As a result, there is no awareness of movement education or attentiveness to other developmental factors. The results of this research showed that suitable, well formed movement programs can develop children's fundamental movement skills. In that way, the importance of movement development before kindergarten school is emphasised. Consequently, educators are being encouraged to utilize children's natural inclination for movement and to integrate organised motor skills programs into their daily schedule. 


\section{References}

Butterfield, S. A., Lehnhard, R. A., \& Coladarci, T. (2002). Age, sex and body mass index index in performance of selected locomotor and fitness tasks by children in grades K-2. Perceptual and Motor Skills, 94, 80-86. http://dx.doi.org/10.2466/pms.2002.94.1.80

Cheung, R. H. P. (2010). Designing movement activities to develop children's creativity in early childhood education. Early Child Development and Care, 180, 377-385. http://dx.doi.org/10.1080 /03004430801931196

Collins, V. K., Miller, S. A., \& Yates, M. (2005). The language arts get physical: Fun, fitness and fundamentals. Dimensions of Early Childhood, 33, 27-32.

Derri, V., Tsapakidou, A., Zachopoulou, E., \& Kioumourtzoglou, E. (2001). Effect of a Music and Movement Programme on Development of Locomotor Skills by Children 4 to 6 Years of Age. European Journal of Physical Education, 6, 16-25. http://dx.doi.org/10.1080/1740898010060103

Evaggelinou, C., Tsigilis, N., \& Papa, A. (2002). Construct validity of the test of gross motordevelopment: A cross-validation approach. Adapted Physical Activity Quarterly, 19, 483-495.

Fjortoft, I. (2000). Motor fitness in pre-primary school children: The EUROFIT motor fitness test explored on 5-7 year old children. Pediatric Exercise Science, 12, 424-436.

Gallahue, D. L. (2002). Developmental physical education for today's children. Thessaloniki: University studio press.

Gallahue, D., \& Ozmun, J. (1998). Understanding motor development: Infants, children, adolescents, adults. Singapore: Mc Graw Hill.

Gellens, S. (2005). Integrate movement to enhance children's brain development. Dimensions of Early Childhood, 33, 14-21.

Hardy, L. L., King, L., Farrell, L., Machiven, R., \& Howlett, S. (2009). Fundamental movement skills among Australian preschool children. Journal of Science and Medicine in Sport.

Kampas, A., Gourgoulis, B., Fatouros, I., Aggelousis, N., Probiadaki, E., \& Taksildaris, K. (2005). Effect psychomotor therapy program on motor performance in preschool children. Physical Education \& Sports, $56,49-59$.

Krombholz, H. (2012). The impact of a 20-month physical intervention in child care centers on motor performance and weight in overweight and healthy-weight preschool children. Perceptual and Motor Skills, 115, 919-932. http://dx.doi.org/10.2466/06.10.25.PMS.115.6.919-932

Linoven, S., Saakslahti, A., \& Nissisen, K. (2011). The development of fundamental motor skills of four to five year-old preschool children and the effects of a preschool physical education curriculum. Early Child Development and Care, 181, 335-343. http://dx.doi.org/10.1080/03004430903387461

Lupu, E. (2011). The role of motric activities in the psycho-motric development of preschool children-future pupils. Procedia Social and Behavioral Sciences, 12, 457-464. http://dx.doi.org/10.1016 /j.sbspro.2011.02.056

Moomaw, S. (2005). Math and science go outside. Dimensions of Early Childhood, 33, $27-32$.

Morris, A. M., Williams, J. M., Atwater, A. E., \& Wilmore, J. H. (1982). Age and sex differences in motor performance of 3 through 6 year old children. Research Quartely for Exercise and Sport, 53, 214-221. http://dx.doi.org/10.1080/02701367.1982.10609342

National Association for Sport and Physical Education (NASPE). (2002). Active Start: A Statement of Physical Activity Guidelines for Children Birth to Five Years. Reston, VA: National Association for Sport and Physical Education Publications.

Natsiopoulou, T., Vidali-Laloumi, E., Zachopoulou, E., Trevlas, E., \& Research Group of Archimedes Project. (2010). An innovative preschool health education program. Health Science Journal, 4, 110-115.

Piek, J. P., Maclaren, S., Kane, R., Jensen, L., Dender, A., Roberts, C., ... Straker, L. (2012). Does the animal fun program improve motor performance in children aged 4-6 years? Human Movement Science.

Pollatou, E., Karadimou, K., \& Gerodimos, V. (2005). Gender differences in musical aptitude, rhythmic ability and motor performance in preschool children. Early Child Development and Care, 175, 361-369. http://dx.doi.org/10.1080/0300443042000270786 
Reilly, J. J., Kelly, L., Montgomery, C., Williamson, A., Fisher, A., McColl, J. H., ... Grant, S. (2006). Physical activity to prevent obesity in young children: cluster randomized controlled trial. British Medical Journal, 333, 1041-1046. http://dx.doi.org/10.1136/bmj.38979.623773.55

Thomas, J. R., \& Thomas, K. T. (1988). Development of gender differences in physical activity. Quest, 40, 219-229. http://dx.doi.org/10.1080/00336297.1988.10483902

Timmons, B. W., Naylor, P., \& Pfeiffer, K. A. (2007). Physical activity for preschool children- how much and how? Applied Physiology, Nutrition and Metabolism, 32, 122-134. http://dx.doi.org/10.1139/H07-112

Toriola, A. L., \& Igbokwe, N. U. (1986). Age and sex differences in motor performance of preschool Nigerian children. Journal of Sports Sciences, 4, 219-227. http://dx.doi.org/10.1080/02640418608732120

Tremblay, M. S., Leblanc, A. G., Carson, V., Choquette, L., Gorber, S. C., ... Timmons, B. W. (2012). Canadian physical activity guidelines for the early years (aged 0-4 years). Applied Physiology, Nutrition and Metabolism, 37, 345-356. http://dx.doi.org/10.1139/h2012-018

Urlich, D. (2000). Test of Gross Motor Development (2nd ed.). Austin, TX: Pro-ed.

Vale, S., Santos, R., Soares-Miranda, L., Silva, P., \& Mota, J. (2011). The importance of physical education classes in pre-school children. Journal of Pediatrics and Child Health, 47, 48-53. http://dx.doi.org/10.1111 /j.1440-1754.2010.01890.x

Venetsanou, F., \& Kambas, A. (2004). How can a traditional Greek dances programme affect the motor proficiency of pre-school children? Research in Dance Education, 5(2), 127-138. http://dx.doi.org $/ 10.1080 / 14617890500064019$

Venetsanou, F., \& Kambas, A. (2010). Environmental factors affecting prescoolers' motor development. Early Childhood Education Journal, 37, 319-327. http://dx.doi.org/10.1007/s10643-009-0350-z

Wang, J. (2004). A study on gross motor skills of preschool children. Journal of Research in Childhood Education, 19, 32-43. http://dx.doi.org/10.1080/02568540409595052

Ward, D. S. (2010). Physical activity in young children: the role of child care. Medicine \& Science in Sports \& Exercise, 42, 499-501. http://dx.doi.org/10.1249/MSS.0b013e3181ce9f85

Zachopoulou, E., \& Makri, A. (2005). A developmental perspective of divergent movement ability in early young children. Early Child Development and Care, 175, 85-95. http://dx.doi.org/10.1080 /0300443042000230401

Zachopoulou, E., Tsangaridou, N., Pickup, I., Liukkonen, J., \& Grammatikopoulos, V. (2007). Early Steps, promoting healthy lifestyle and social interaction through physical education activities during preschool years. Thessaloniki: Christodoulidi publications.

Zachopoulou, E., Tsapakidou, A., \& Derri, V. (2004). The effects of a developmentally appropriate music and movement program on motor performance. Early Childhood Research Quarterly, 19, 631-642. http://dx.doi.org /10.1016/j.ecresq.2004.10.005

\section{Copyrights}

Copyright for this article is retained by the author(s), with first publication rights granted to the journal.

This is an open-access article distributed under the terms and conditions of the Creative Commons Attribution license (http://creativecommons.org/licenses/by/3.0/). 